
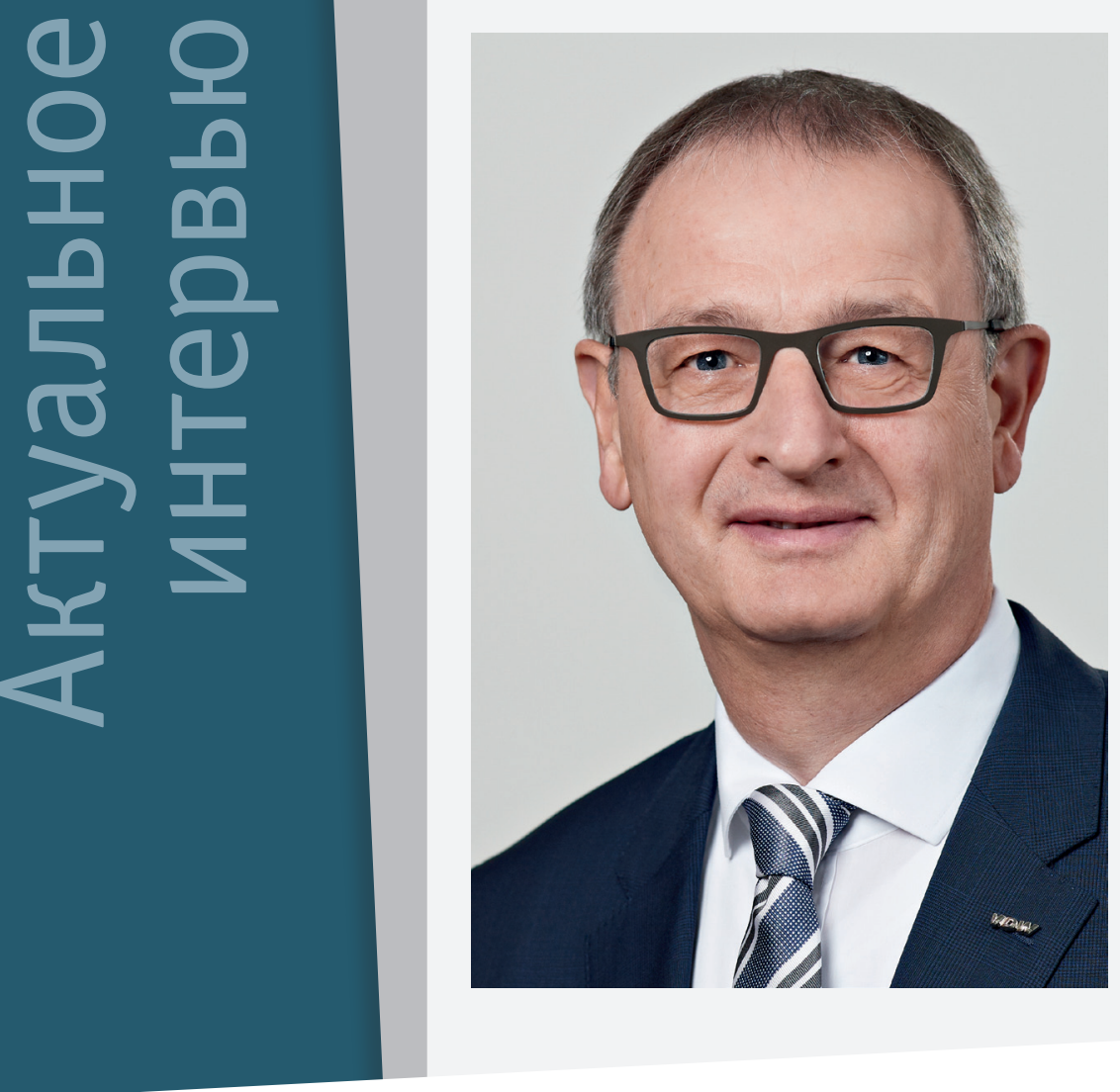

Согласно прогнозам британского Института экономических исследований Oxford Economics, мировая экономика в начале года выросла на 2,5\%. Рост инвестиций и промышленного производства в этом году достигнет 2,4\%. Согласно весеннему прогнозу, рост потребления станков составит $2,3 \%$. На этом фоне в России проходит выставка «Металлообработка-2019», а в Германии состоится «ЕМ0 Hannover 2019». Смогут ли эти два столпа мирового станкостроения стать драйверами роста и разогреть мировую экономику?

\title{
«МЕТАЛЛООБРАБОТКА» И ЕМО-2019 - ДВА СТОЛПА МИРОВОГО СТАНКОСТРОЕНИЯ ИНТЕРВЬЮ С ВИЛЬФРИДОМ ШЕФЕРОМ, ДИРЕКТОРОМ СОЮЗА СТАНКОСТРОИТЕЛЕЙ ГЕРМАНИИ (VDW)
}

\section{- Вы ВозглаВляете крупный союз немецких} станкостроительных компаний, какие основные принципы лежат В осноВе этого союза?

- Принципы нашего объединения состоят в том, что это добровольный союз, все участники выразили свое желание вступить в него на добровольных началах. Нас оценивают по результатам нашей деятельности, и мы прилагаем все усилия, чтобы добиться успешности наших компаний. Мы представляем сферу услуг в области индустрии и промышленности, поскольку многие компании не имеют отделов, которые занимались бы рекламой и информационной поддержкой. Мы нужны для того, чтобы проводить рыночные исследования, накапливать статистику и следить за стратегиями развития на мировых рынках.
- Сколько компаний Входит В союз В настоящее время?

- Примерно 240 компаний, но нужно учесть, что в это число входят поставщики и разработчики программного обеспечения. Что касается производителей станков, то это 85-90\% компаний, работающих в этой сфере на немецком рынке.

- Как даВно Вы работаете с российским рынком?

- Более 30 лет, начиналось сотрудничество еще во времена СССР. Мы поддерживаем эту выставку («Металлообработка-2019»), начиная еще с самой первой выставки, прошедшей 35 лет назад. А до нее, лет 40 назад, мы провели свою собственную выставку в СССР. Последние 15 лет мы в год проводим по два симпозиума за пределами Германии, и если говорить о России, то эти мероприятия проходили 
в Самаре, Екатеринбурге, Санкт-Петербурге, Москве, причем в некоторых из этих городов - уже два раза. Представители нашего союза приезжают в Россию на два дня, читают лекции, встречаются с потенциальными клиентами.

\section{- Каковы практические результаты этих} Выставок и симпозиумов?

- Я хочу отметить активное участие наших компаний в таких мероприятиях. Мы постоянно занимаемся мониторингом рынка и собираем статистические данные. В течение последних 12 лет Россия занимала третье место на рынке потребителей нашей продукции. За последние три года ситуация несколько изменилась, в связи с общим снижением инвестиционной деятельности после 2014 года. Сейчас Россия находится на 11 месте по объему закупок станкостроительного оборудования из Германии. Мы получаем значительное количество заказов из России, объем которых в 2017 году составил 257 млн евро (в 2014 году - 488 млн евро). В прошлом году Россия потратила на металлообрабатывающие станки 1,3 млрд евро. Согласно статистике союза VDW три четверти из этой суммы пришлось на импорт. Важнейшим поставщиком является Германия, оставив далеко позади Китай, Италию, Тайвань и Японию. В 2018 году, согласно статистике внешней торговли, Германия поставила оборудования на сумму 278 млн евро, в первую очередь это металлообрабатывающие центры, токарные станки, а также детали и комплектующие к ним. В 2018 году поставки из Германии выросли на 8\%. По данным опроса VDW, в текущем году ожидается некоторое снижение оборота из-за уменьшения количества поступающих из России заказов на поставку немецких станков.

- ЯВляется ли ВыстаВка ЕМО Возможностью для российских компаний Выйти на немецкий рынок?

- Да, конечно. Это исключительная возможность, выставка ЕМО - это наиважнейшая выставка как для Германии, так и для всего мира.

\section{- Расскажите о ЕМО-2019 немного подробнее.}

- Это важнейшая выставка не только в Германии, но и во всем мире. ЕМО-2019, международная выставка в области металлообработки, пройдет с 16 по 21 сентября в Ганновере. Она организована VDW, базирующимся в Франкфурте-на-Майне (Германия) по поручению Европейской ассоциации станкостроителей Сесіто из Брюсселя, при сотрудничестве с компанией Deutsche Messe AG (Ганновер, Германия). VDW является представителем немецкой станкостроительной промышленности и одной из немногих отраслевых ассоциаций, которая проводит международные ярмарки по своему собственному направлению. Благодаря этому мы обладаем многолетним опытом. Знак качества «Выставка VDW» стал символом успешных мероприятий. Наряду с выставкой EMO Hannover к ним относятся METAV в Дюссельдорфе и Международная выставка технологий в области металлообработки (срок проведения: 10-13 марта 2020 года).

Союз VDW вместе с отраслевым союзом производителей станков и технологических систем при VDMA (Союз машиностроителей Германии) включает около 300 членов, объединенных на добровольных началах.

Будучи организатором выставки ЕMO Hannover 2019, союз VDW в сотрудничестве с Deutsche Messe AG предлагает посетителям и экспонентам широкий спектр услуг: онлайн-регистрацию посетителей и участников выставки, предоставление информации о представительстве Deutsche Messe AG на местном языке, поддержку по визовым вопросам, привлекательные предложения на авиаи железнодорожные поездки для посетителей выставки ЕМО, онлайн-информацию на девяти языках, индивидуальное обслуживание иностранных делегаций, тематические туры и многое другое. В 2017 году на ЕМО было зарегистрировано 2200 участников, представлявших свою продукцию на 180 тыс. кв. м, что в пять раз больше, чем нынешняя выставка «Металлообработка-2019». Примерно 130 тыс. посетителей, около 50\% - это участники не из Германии, это означает, что российские участники имеют возможность встретиться с потенциальными партнерами и клиентами со всего мира.

- Как удается работать В услоВиях экономических и политических санкций, ВВеденных В отношении России?

- Конечно, сейчас приходится работать в несколько других, более сложных условиях, но следует помнить о том, что санкции касаются не всех видов продукции, а лишь некоторых видов станков и определенных производителей и компаний. Что касается других областей, то там работа идет очень активно, наблюдается рост взаимоотношений между странами, что мы регулярно отмечаем и публикуем в наших ежегодных отчетах. Мы пытаемся генерировать новые связи и контакты, и в этой работе мы небезуспешны.

\section{- Какая продукция наиболее Востребована} в Pоссии?

- Это обрабатывающие центры, токарные станки, зуборезные станки, шлифовальные машины, а если говорить в общем, то характер распределения продукции, закупаемой Россией, соответствует общей картине мирового потребления нашей продукции. 
- Ориентированы ли компании, Входящие В Ваш союз, на создание произВодств на территории России?

- Я сказал бы, скорее, нет, поскольку внутренний рынок России пока не так велик, чтобы организовывать тут производство. Речь идет о малых и средних предприятиях, которые не могут себе позволить локализовывать производство во многих странах мира. По немецким масштабам, мелкие и средние компании насчитывают до 250 работников. Для сравнения экспортный объем китайского рынка - более 2 млрд евро в год, то есть этот объем превышает российский в 50 раз. Поэтому крупные предприятия уже имеют на территории Китая свои филиалы, поскольку рынок больше. DMG MORI - единственный завод, который построен в России, этого мало, но есть перспективы, это проблемы роста.

\section{- Cпособствует ли Выставка работе Вашего} союза по обучению российских спечиалистов?

- Наше объединение организовало в 2009 году компанию, занимающуюся обучением подрастающего поколения, молодых специалистов. Есть два направления ее деятельности - первое это проинформировать и заинтересовать молодых людей техническими профессиями: например, на ЕМО будет стенд площадью 1000 кв. м, на котором посетители, около 6500 школьников, собирают модель скоростного болида для Формулы-1. Технологии очень быстро развиваются и поэтому второе важное для нас направление - это обучение преподавателей, которые работают в средних специальных учебных заведениях и непосредственно на предприятиях. Там им показывают новейшие технологии производства, раздают материалы, которые могут быть использованы в работе по обучению студентов среднеспециальных учебных заведенияй. В течение трех лет мы разрабатывали проект обучающей платформы на планшетах, который заработал с прошлого года. Мы создали программное обеспечение, с помощью которого учителя заранее могут загрузить в планшеты задание, чертежи, документацию, а на занятиях студенты могут посмотреть это задание, какую часть им необходимо изготовить, подойти с планшетом к станку, с помощью камеры распознать и скачать по QR-коду инструкцию по эксплуатации, использовать другие функции для выполнения задания.

\section{- Поддерживаете ли Вы движение рабочих про- фоессий?}

- Мы являемся членами немецкого движения WorldSkills и поддерживаем его, но мы пока не очень активны.

В 2014 году у нас были переговоры с российским правительством по поводу создания в России образцового профессионально-технического училища и исполь- зования его в качестве пилотного проекта, но, к сожалению, не получили дальнейшую поддержку с российской стороны. Сейчас мы работаем с фондом поддержки подрастающего поколения. Мы обучили преподавателей из Италии, осуществляем один проект училища в Нигерии, то есть мы работаем и за рубежом.

\section{- Что Вы хотели бы сказать читателям журна-} ла «СТАНКОИНСТРУМЕНТ》 и Всем заинтересоВанным лицами В России?

- У нас есть еще два направления нашей деятельности - Интернет вещей и «Индустрия 4.0». Для нас было большим удивлением, что в 2017 году на выставке ЕMO-2017 произошел большой всплеск интереса к Интернету вещей и «Индустрии 4.0». Мы наблюдали и наблюдаем уже целый год повышенный интерес к этим направлениям и, конечно, не можем не реагировать на такой запрос рынка. Мы продумали и создали целый раздел на выставке, посвященный этим направлениям, он будет посвящен умным инструментам и компонентам, программному обеспечению и коммуникациям в новой парадигме «Индустрии 4.0».

\section{- Coтрудничаете ли Вы с научными иентрами в Poсcиu?}

- В данный момент у нас нет кооперации с российскими учеными, но есть собственные центры и исследовательские лаборатории в наших университетах, крупных исследовательских центрах. В 2017 году мы начали работу над проектом по созданию универсального комплексного интерфейса ОРC UA (OPC Unified Architecture). В настоящее время есть интерфейсы, жестко связанные с оборудованием, например Siemens и др. Новый универсальный комплексный интерфейс создан как пилотная версия, содержащая 100 параметров. Эта пилотная версия будет размещена для обсуждения и согласования так называемой рабочей группой Joint Group. Сейчас в группе работают 70 представителей стран мира. К обсуждению могут присоединиться как российские фирмы, так и российские ученые. Мы пригласим любого, кто направит нам заявку на участие в работе этой группы. Группа работает также в режиме онлайнконференций и семинаров, коммуникация идет по Интернету, так что участникам не надо собираться в каком-либо месте, взаимодействие идет очень активно в дистанционном режиме. Пока проработали только 20 параметров из 100, что явно недостаточно. Работы будут интенсифицированы после окончания EMO-2019, и мы приглашаем к сотрудничеству всех заинтересованных лиц. Нам не хотелось бы, чтобы из этого получился бумажный документ, стандарт, мы хотим показать, как с его помощью можно на выставке ЕМО провести демопоказ, объединив 50 станков в одну IT-систему. В рамках программы «Зона 
«Индустрии 4.0» инновационные предприятия и НИИ представляют интеллектуальные решения для успешного ведения бизнеса. Это могут быть интеллектуальные компоненты для контроля технологических операций или поддержки оператора, решения, обеспечивающие бесперебойный поток данных при их максимальной защите и т. д. Специальный раздел посвящен работе исследователей, которые должны показать текущий уровень развития научной мысли. На специализированном форуме будет возможность обсудить с широкой профессиональной аудиторией реализованные предложения и видение будущего. Разработкой специального раздела занимаются союз VDW и медиагруппа Konradin.

На выставке EMO Hannover 2019 будет представлен стандарт интерфейса для металлообрабатывающих станков на базе OPC UA со всеми сопутствующими функциями. Он обеспечивает нейтральное, открытое подключение машин к ИТ-системам более высокого уровня. Это является условием успешности концепции «Индустрия 4.0». Только тогда данные машин разных производителей с различными системами управления могут быть переданы в системы ERP и MES или в облако, где будут обработаны и проанализированы, сформируется основа для новых сервисов и функций.

Реализация универсального интерфейса является ключом к получению дополнительной прибавочной стоимости ценностей и созданию бизнес-моделей, которые экономика надеется получить в рамках «Индустрии 4.0». Малым предприятиям нужна возможность просто объединить свое оборудование в сеть, чтобы участвовать и воспользоваться преимуществами новых разработок Интернета вещей и сконцентрироваться на внедрении соответствующих ноу-хау.

Вот почему союз VDW вместе с восемью известными немецкими производителями станков и всеми основными поставщиками систем управления более года назад запустили интерфейс umati. Эта аббревиатура расшифровывается как «универсальный интерфейс металлообрабатывающих станков». На сегодняшний день было определено 20 вариантов применения, например, быстрый осмотр производства, состояние программы и станка, обработка производственного заказа, создание статистики ошибок или отображение рабочего состояния в виде диаграммы. Сейчас международное сообщество производителей металлообрабатывающих станков может участвовать в изменении и распространении этого стандарта. Наша цель - полностью представить на EMO Hannover 2019 доступную на данный момент версию в полном объеме - причем наибольшему количеству партнеров. Союз VDW исходит из того, что на данном этапе предлагаются продукты, в которых предварительно настроенные серверы OPC-UA интегрированы непосредственно в соответствующие контроллеры в соответствии со спецификацией.
- Появится ли Возможность дистанционного контроля и диагностики станкоВ, работающих под управлением этого интерфеейса?

- Да, конечно, но это зависит от того, захочет ли тот или иной производитель выводить данные за пределы своего производства.

- Есть ли отличия потребления российского рынка от европейского по составу заказов?

- Нет, таких отличий нет. Все современные технологии востребованы на российском рынке так же, как и на европейском.

- Как скоро будет Востребована "Индустрия 4.0» В России?

- Предсказать трудно, в Европе это пока также не очень распространено, 20 лет назад станки уже были соединены в сети, но ведь не в этом суть «Индустрии 4.0», речь идет о другом - нужно собрать данные о работе двигателей, показания датчиков, сенсоров производственного процесса, проанализировать и предсказать то, что еще не случилось.

- Планируется ли использование искусстВенного интеллекта?

- Вначале надо сделать домашнее задание сегодняшнего дня. А потом привлекать новые возможности. Если у производителя есть уже 10 , 20 новых станков, суть в том, чтобы собрать данные со всех станков и спрогнозировать то, что может произойти в будущем - заполнится склад, ухудшится качество и т. д. Многие производители не хотят, чтобы их данные утекали в облачные хранилища, не хотят делиться своей статистикой. Так что проблема не в том, чтобы объединить станки, а в том, чтобы подготовить все условия для массового сбора данных и прогнозирования будущего. Решающим значением для работы умного завода является создание всеохватывающей сети, объединяющей людей, оборудование и бизнес-процессы по всей цепочке создания стоимости, независимо от систем управления.

\section{- Каковы Ваши планы разВития В России?}

- Ежегодно мы участвуем в выставке «Металлообработка», организовываем наше участие тут через министерства. Мы продолжим эту полезную для наших стран работу и изучим возможность проводения симпозиума в России.

Большое спасибо за интересную беседу, мы заблаговременно проинформируем читателей о всех грядущих событиях, которые организует ваш союз в России!

С Вильфридом Шефером беседовали А.Н. Алёшин и О.А. Лаврентьева 